Submitted to JMR: Invited Feature Paper (April 2018): Revised: May 2018

\title{
Fabrication of Nanocomposite through Diffusion Bonding under High-Pressure Torsion
}

\author{
Megumi Kawasaki ${ }^{1 *}$, Jae-Kyung Han ${ }^{1}$, Dong-Hyun Lee ${ }^{2}$, Jae-il Jang ${ }^{2}$, Terence G. Langdon ${ }^{3}$ \\ ${ }^{1}$ School of Mechanical, Industrial \& Manufacturing Engineering, Oregon State University, \\ Corvallis, OR 97331-6001, U.S.A. \\ ${ }^{2}$ Division of Materials Science and Engineering, Hanyang University, Seoul 04763, \\ Republic of Korea \\ ${ }^{3}$ Materials Research Group, Faculty of Engineering and the Environment, \\ University of Southampton, Southampton SO17 1BJ, U.K.
}

\begin{abstract}
This report summarizes a recent study demonstrating simple and rapid synthesis of a new Al$\mathrm{Mg}$ alloy system and ultimately synthesizing a metal matrix nanocomposite (MMNC) which was achieved by processing stacked disks of the two dissimilar metals by conventional highpressure torsion (HPT) processing. The synthesized Al-Mg alloy system exhibits exceptionally high hardness through rapid diffusion bonding and simultaneous nucleation of intermetallic phases with increased numbers of HPT turns through 20 and improved plasticity was demonstrated by increasing strain rate sensitivity in the alloy system after postdeformation annealing. An additional experiment demonstrated that the alternate stacking of high numbers of dissimilar metal disks may produce a faster metal mixture during HPT. Metal combinations of $\mathrm{Al}-\mathrm{Cu}, \mathrm{Al}-\mathrm{Fe}$ and $\mathrm{Al}-\mathrm{Ti}$ were processed by the same HPT procedure from separate pure metals to examine the feasibility of the processing technique. The microstructural analysis confirmed the capability of HPT for the formation of heterostructures across the disk diameters in these processed alloy systems. The HPT processing demonstrates a considerable potential for the joining and bonding of dissimilar metals at room temperature and the expeditious fabrication of a wide range of new metal systems.
\end{abstract}

Keywords: Al-Mg; diffusion bonding; high-pressure torsion; intermetallic compound; severe plastic deformation 


\section{INTRODUCTION}

The synthesis of new generation metals and alloys is now driven by technological issues combined with the restrictions imposed by ecological considerations in a variety of industrial applications [1]. Aluminum and magnesium are conventional light-weight engineering metals and they are widely used for structural applications in the automotive, aerospace and electronic industries. Further consuming these conventional metals, improvements in the mechanical properties of these metals would be attractive for enhancing their future use. In practice, an earlier study demonstrated an increase in the strength limit of an aerospace-grade Al-7075 alloy after the grain refinement process through the application of high-pressure torsion (HPT) while maintaining reasonable formability [2]. Nevertheless, there is probably saturation in the maximum achievable mechanical properties when the processing are conducted directly on the alloys. This suggests a new strategy for achieving superior properties of engineering metals by bonding dissimilar metals during grain refinement processing and synthesizing new metal systems.

Application of severe plastic deformation (SPD) is a promising approach for processing bulk nanostructured materials (BNM) with ultrafine grains [3]. A growing interest in the research field has arisen in the last two decades and ultrafine-grained (UFG) materials processed through SPD are referred to as interface-controlled materials where the grain boundaries are specially arranged by severe straining leading to superior mechanical and functional properties [4]. Among the reported numerous SPD techniques to date [5], one of the most attractive methods refers to processing by HPT [6] where this processing procedure leads to exceptional grain refinement that is not generally achieved using other procedures [7]. In practice, a bulk metal in a disk shape is severely strained under extreme pressure with concurrent torsional straining and the processing is often conducted for hard-to-deform metals including bulk intermetallic compounds [8-11] at room temperature (RT). Because of 
the intensive introduction of point and line defects during the significant grain refinement process, HPT has been applied also for the bonding of machining chips $[12,13]$ and the consolidation of metallic powders [14-19]. Nevertheless, these processes generally require high processing temperatures and/or two-step processes for cold/hot compaction prior to consolidation by HPT.

Accordingly, a new approach of applying conventional HPT processing into the cladding process was studied very recently for synthesis of hybrid nanostructured metallic materials. Specifically, separate $\mathrm{Al}$ and $\mathrm{Mg}$ are processed concurrently and the unique microstructure, hardness evolutions and the micro-mechanical response are described for an Al-Mg hybrid system synthesized by HPT [20-22]. Moreover, a study of post-deformation annealing (PDA) was applied to demonstrate the improvement in plasticity by an increase in the strain rate sensitivity, $m$, in the synthesized alloy system [23]. Thus, the next section summarize these recent experimental findings on the formation of an $\mathrm{Al}-\mathrm{Mg}$ hybrid system and ultimately fabricating a metal matrix nanocomposite (MMNC) from separate $\mathrm{Al}$ and $\mathrm{Mg}$ disks through diffusion bonding at RT during HPT. Moreover, the following discussion section describes the feasibility of the HPT processing approach by changing a sample set-up and the potential of the HPT technique for synthesizing new metal systems.

\section{FABRICATION OF AN Al-Mg HYBRID SYSTEM}

A series of experiments used two separate dissimilar metals of a commercial purity Al-1050 and a ZK60 magnesium alloys. The extruded bars of theses alloys with a diameter of $10 \mathrm{~mm}$ were cut into billets having lengths of $\sim 65 \mathrm{~mm}$ and a number of disks was sliced from the billets and polished to achieve uniform thicknesses of $\sim 0.8 \mathrm{~mm}$. Processing by HPT was performed on these two materials for direct bonding at RT under a quasi-constrained condition [24]. In practice, the alloys were stacked in the depression on the lower anvil in the 
order of $\mathrm{Al} / \mathrm{Mg} / \mathrm{Al}$ without any special adhesion treatment and these were processed under 6.0 GPa for 1, 5, 10 and 20 turns at a rotational speed of $1 \mathrm{rpm}$.

Several sets of the metals were processed by HPT and the cross-sections of the disks were examined by an optical microscopy $(\mathrm{OM})$ and the hardness distributions over the crosssections were examined by a Vickers microhardness tester. Figure 1 shows the observed OM micrographs for the disks of the Al-Mg alloy system after HPT for, from the top, 1, 5, 10, 20 turns and 20 turns followed by PDA at $573 \mathrm{~K}$ for 1 hour, respectively [20-23]. The bright regions denote the Al-rich phase and the dark regions correspond to the $\mathrm{Mg}$-rich phase in these OM micrographs. The color-corded hardness contour maps are overlapped on the right half of each OM micrograph by considering the general characteristics of the radial sympatry in microstructural evolution, thus hardness distribution, within the processed disks due to torsion straining during HPT [25].

The cross-section after HPT for 1 turn showed a simple multi-layered structure with a necked and fragmented Mg layer with thicknesses of $\sim 200 \mu \mathrm{m}$ without any segregation between the $\mathrm{Al}$ and $\mathrm{Mg}$ phases throughout the disk diameter. A similar microstructure consisting of the Al-Mg multi-layers was observed at the central area at $r<2.0-3.0 \mathrm{~mm},<1.5-$ $2.0 \mathrm{~mm}$ and $<1.5 \mathrm{~mm}$ of the disks after 5, 10 and 20 turns, respectively, where $r$ denotes the radius of the HPT disk. After the PDA treatment, the central region with the large $\mathrm{Al}$ and $\mathrm{Mg}$ layers exist in a wider region at $r<3.5 \mathrm{~mm}$.

On contrary, there is a homogeneous distribution of very fine $\mathrm{Mg}$ phases having thicknesses of $\sim 5-10 \mu \mathrm{m}$ to even true nano-scale sizes of $\sim 100-500 \mathrm{~nm}$ at the disk peripheries at $r>2.5 \mathrm{~mm}$ after 5 turns. Additional HPT to 10 turns, these $\mathrm{Mg}$ phases disappeared at the disk edge and thus there was no evidence of visible $\mathrm{Mg}$ phases at $\sim 3.0<r<5.0 \mathrm{~mm}$ of the processed disk. The unique microstructure without the $\mathrm{Mg}$-rich phase remained constant at the disk peripheries at $r>3.0 \mathrm{~mm}$ after 20 turns and $r>4.0 \mathrm{~mm}$ after additional PDA. 
The color-coded hardness contour maps were constructed from a series of the hardness data set for the cross-sections after HPT. For references, the base materials of Al1050 and the ZK60 alloys achieve a saturation hardness of $\mathrm{Hv} \approx 65$ [26] and $~ 110$ [27] across the disk diameters after conventional HPT processing for 5 turns providing sufficient torsional straining. After 1 turn, the hardness distribution over the total cross-section showed an average of $\mathrm{Hv} \approx 70$. This is similar to the saturated hardness value of the base Al alloy after HPT and this hardness value remains constant at the centers at $r<2.5 \mathrm{~mm}$ of the Al-Mg disks up to 10 turns and $r<2.0$ after 20 turns.

However, 5 turns by HPT introduced high hardness with a maximum of $\mathrm{Hv} \approx 130$ in the peripheral region at $r>3.5 \mathrm{~mm}$ where the fine $\mathrm{Mg}$ phase is homogeneously distributed within the Al matrix. Moreover, significant increase in hardness with a maximum of $\sim 270$ was observed at the disk edge at $r>4.0 \mathrm{~mm}$ after 10 turns where there is no more $\mathrm{Mg}$-rich phases in the $\mathrm{Al}$ matrix. Continuous increase in hardness was further observed at the disk periphery after HPT for 20 turns. Specifically, a transition in hardness was measured from $\sim 150-240$ at $r \approx 2.5-3.5 \mathrm{~mm}$ to an exceptionally high hardness of $\mathrm{Hv} \approx 330$ at $r \approx 4.0-5.0 \mathrm{~mm}$. After PDA, there was a slight reduction in hardness to $\mathrm{Hv} \approx 220$ at the outer region of the disk at $r \approx 4.0-5.0 \mathrm{~mm}$. Subsequently, the changes in microstructure observed by $\mathrm{OM}$ correlate directly with the values of hardness in the Al-Mg system after HPT and there is a significant hardness variation in the synthesized Al-Mg system through HPT processing. In addition, these high hardness at the disk edges in the Al-Mg system for more than 5 turns by HPT are much higher than the saturated high hardness of the base materials of $\mathrm{Al}$ and $\mathrm{Mg}$ after conventional HPT and thus a detailed microstructural analysis is necessary to understand the hardening mechanisms of the unique Al-Mg system produced by HPT.

The detailed microstructural analysis was conducted using transmission electron microscopy (TEM) where the samples were prepared by applying a focused ion beam at $r \approx$ 
$4.5 \mathrm{~mm}$ and X-ray diffraction (XRD) analysis at the disk edges of the Al-Mg system after HPT up to 20 turns and processing followed by PDA. Selected results are shown in Figs 2 and 3. Specifically, TEM micrographs taken for the disk edges after 5 and 10 turns are shown in Fig. 2(a) [20-22] and (b) [20,21], respectively, and the local microstructural information [28] by the XRD analysis for of the disk edge after 10 turns are shown in Fig. 2(c) [20,21]. The TEM micrographs at the disk peripheries are displayed in Fig. 3 for the samples after (a)(b) 20 turns and (c) HPT followed by PDA, and the XRD profiles for these two samples are shown in Figure 3(d) and (e), respectively [22].

After 5 turns, the $\mathrm{Al}$ matrix phase consists of a layered nanostructure with thicknesses of $\sim 90-120 \mathrm{~nm}$ and the average spatial grain size, $d$, in the Al matrix phase was $\sim 190 \mathrm{~nm}$. As indicated in Fig. 2(a), there is a single visible Mg phase in the TEM micrograph and it has a homogeneous bonding interface with the Al matrix without any visible voids. Moreover, within the matrix phase there were several very thin layers with an average thickness of $\sim 20$ $\mathrm{nm}$ as indicated by the white arrows. Close inspection through quantitative chemical analysis revealed in an earlier study that the thin layers are composed of $66-78$ at.\% $\mathrm{Al}$ and $24-30$ at.\% $\mathrm{Mg}$, thereby suggesting an intermetallic compound of $\beta-\mathrm{Al}_{3} \mathrm{Mg}_{2}$ [20] which has a low density of $\sim 2.25 \mathrm{~g} / \mathrm{cm}^{3}$ [28]. Since the thin layers existed irregularly in the Al matrix [21], HPT processing formed an intermetallic-based MMNC in the Al-Mg system at the disk edge after 5 turns.

As mentioned earlier, there was no evidence of a Mg-rich phase at the disk edge after HPT for 10 turns and the microstructure is shown in Fig. 2(b) with a spatial grain size of $\sim 90$ nm. An XRD analysis with Materials Analysis Using Diffraction (MAUD) analysis [29] for identifying and quantifying the amounts of existing compounds revealed the formation of another intermetallic compound of $\gamma-\mathrm{Al}_{12} \mathrm{Mg}_{17}$ with a volume fraction of over $20 \%$ in the $\mathrm{Al}$ matrix at the disk edge, while a presence of very small amount of $\beta-\mathrm{Al}_{3} \mathrm{Mg}_{2}$ with $<5 \mathrm{vol} . \%$ 
was not observed in the X-ray analysis. It should be noted that the detected Mg-rich phase of $\sim 5$ vol.\% through the MAUD analysis is inevitable because of the large Mg-rich phases existed close to the mid-radius at $r \approx 2.5-3.0 \mathrm{~mm}$ after removing the central regions following the earlier XRD sample preparation [27].

Figure 3(a) and (b) show two representative microstructures taken at a layeredstructure region and an equiaxed grain region at the disk edge immediately after HPT for 20 turns. In practice, the layered microstructure has an average thickness of $\sim 20 \mathrm{~nm}$ and these layers contain numerous dislocations which subdivide the layers in a vertical sense. The equiaxed grains showed an average grain size of $d \approx 60 \mathrm{~nm}$. By contrast, after PDA it is seen in Fig. 3(c) that the Al-Mg system contained a homogeneous equiaxed microstructure with an average grain size of $d \approx 380 \mathrm{~nm}$.

The results of the X-ray analysis are shown in Fig. 3(d) and (e) where additional compositional analysis based on the X-ray profile through MAUD was displayed as a table in each plot. The disk edge immediately after HPT for 20 turns showed there is evidence of a $\gamma$ $\mathrm{Al}_{12} \mathrm{Mg}_{17}$ intermetallic compound in the $\mathrm{Al}$ matrix whereas after PDA there is an $\mathrm{Al}-7 \% \mathrm{Mg}$ solid solution phase with two different $\beta-\mathrm{Al}_{3} \mathrm{Mg}_{2}$ and $\gamma-\mathrm{Al}_{12} \mathrm{Mg}_{17}$ intermetallic compounds. Thus, processing by HPT for 20 turns and additional PDA produced two different types of SPD-induced MMNCs containing intermetallic compounds at the disk edges of the Al-Mg system.

\section{MICRO-MECHANICAL PROPERTIES}

From the Vickers microhardness results, it is apparent that the disk edges after HPT became hard due mainly to grain refinement and formation of several ultrafine intermetallic compounds forming MMNCs. It is reasonable to evaluate the change in plasticity with addition of PDA in the Al-Mg system after HPT for 20 turns. Specifically, the novel technique of nanoindentation is applied for measuring the micro-mechanical properties at the 
disk edges consisting of MMNCs in the Al-Mg system after HPT for 20 turns and subsequent PDA. The applied nanoindentation facility holds a three-sided pyramidal Berkovich indenter having a centerline-to-face angle of $65.3^{\circ}$ and more than 15 indentations were conducted at each measured location to provide statistically valid data. All measurements were conducted under a predetermined peak applied load of $P_{\max }=50 \mathrm{mN}$ at constant indentation strain rates of $0.0125,0.025,0.05$ and $0.1 \mathrm{~s}^{-1}$ which are equivalent to general strain rates of $1.25 \times 10^{-4}$, $2.5 \times 10^{-4}, 5.0 \times 10^{-4}$ and $1.0 \times 10^{-3} \mathrm{~s}^{-1}$ calculated through an empirical relationship [30].

Representative load-displacement curves are shown in Fig. 4(a) for the Al-Mg disk edges after HPT for 20 turns and HPT followed by PDA when measuring at four strain rates [22]. There are two important results observed from the plot. First, it is apparent by comparing the load-displacement curves between the two samples that the MMNC immediately after HPT shows much lower displacements than the MMNC after PDA at all strain rates, thereby demonstrating high hardness of the MMNC in the Al-Mg disk edge immediately after HPT for 20 turns. This result is in good consistency with the results for Vickers hardness as shown in the color-coded hardness maps in Fig. 1. Secondly, the disk edge after HPT for 20 turns demonstrated no strain rate dependency where all four loaddisplacement curves placed in reasonably consistent locations, while the material after PDA demonstrated a distinct positive strain rate dependency where increasing displacements were achieved with decreasing strain rate.

For quantifying the dependency on strain rates, the series of the nanoindentation data were analyzed by considering Tabor's empirical prediction where considering the Tabor's empirical prediction where the flow stress is equivalent to one-third of hardness, $H$, measured through nanoindentation testing for fully-plastic deformation at a constant strain rate [31]. Thus, as shown in Fig. 4(b), the strain rate sensitivity, $m$, can be determined from the slope of a line in a logarithmic plot of $H / 3$ against the strain rate for each disk edge of the Al-Mg 
system after HPT for 20 turns and after HPT followed by PDA [22]. The estimations suggest the $m$ values of -0.001 and 0.1 for the MMNCs at the Al-Mg disk edges immediately after HPT for 20 turns and after HPT followed by PDA, respectively. A significant loss of ductility was well documented earlier in bulk nanostructured materials where instead a marked increase in hardness and strength is achieved by grain refinement through SPD [32-36]. Nevertheless, this nanoindentation analysis proved that there is a significant increase in the strain rate sensitivity in the SPD-induced MMNC by the PDA treatment. Thus, the heat treatment is capable for enhancing the plasticity at RT in the MMNC in the Al-Mg hybrid system synthesized by HPT while maintaining reasonably fine microstructure with high hardness as shown in Figs 1 and 3. It should be emphasized that the improved $m$ value in the $\mathrm{Al}-\mathrm{Mg}$ system is even higher than several UFG metals of $\sim 0.07$ for a commercial purity $\mathrm{Al}$ after ECAP for 6-12 passes at RT [37-40] and after ARB for 8 cycles at RT [38] and $~ 0.035-$ 0.050 for a ZK60 alloy after HPT for 2 turns at RT [41]. Thus, the MMNC after HPT followed by PDA demonstrates a significantly higher value of $m$ compared with the base metals when they are processed separately. It should be noted that the nanoindentation technique provides sufficient estimation of the strain rate sensitivities for evaluating the plasticity and ductility of nanostructured metals and it was summarized in a recent review on the micro-mechanical response on SPD materials measured by nanoindentation [42].

An earlier study demonstrated the significance of PDA for improving the overall ductility of nanostructured Ti after HPT [43]. In practice, a PDA treatment produces an ordering of the defect structures within the grain boundaries leading to an equilibrium state without any significant grain growth [35]. Moreover, short-term annealing after severe straining by SPD reduces the dislocation density in the grain interior of the UFG material so that the dislocation storage capability is anticipated to increase leading to enhancement in the strain hardening capability for high ductility in the SPD-processed material. Accordingly, by 
the addition of a PDA treatment, the MMNC in the Al-Mg system produced by HPT has a great potential for demonstrating both high hardness and superior ductility.

\section{DISCUSSION}

\section{A. Physical and mechanical evolutions, and sample set-up for HPT}

Beside the formation of new metal systems in terms of microstructural and hardness evolutions, it is necessary to analyze the change in an essential physical property of density at the disk edges in the Al-Mg system during processing by HPT. This analysis can ultimately estimate the strength-to-weight ratio of the formed MMNCs in the Al-Mg system by means of the values of hardness measured in earlier section. Accordingly, the density was measured at the disk edges consisting of MMNCs in the Al-Mg systems after HPT for 5, 10 and 20 turns and the strength-to-weight ratio was estimated for each material which are shown in Table 1 [44]. For comparison purposes, the measurements are also conducted on the reference materials of the Al-1050 and ZK60 alloys after HPT for 5 turns. The values of density were measured directly from the volume and weight of each sample disk.

It is apparent that the density for the MMNCs in the Al-Mg disk edges decreases with increasing HPT turns where there is a concurrent occurrence of diffusion bonding, a reduction in the $\mathrm{Mg}$-rich phases and the formation of intermetallic compounds. Due to the lowered density, the Al-Mg system after 10 and 20 turns demonstrated an excellent strengthto-weight ratio of $\sim 350$ and $455 \mathrm{MPa} \mathrm{cm}^{3} \mathrm{~g}^{-1}$, respectively, and these values are significantly higher than the base materials of the $\mathrm{Al}$ and $\mathrm{Mg}$ alloys. In fact, this value is significantly higher than any other structural metals including steels showing $\sim 150 \mathrm{MPa} \mathrm{cm}^{3} \mathrm{~g}^{-1}$ and similar to the engineering polymeric composites, ceramics and carbon fibers showing $\sim 200 \mathrm{MPa}$ $\mathrm{cm}^{3} \mathrm{~g}^{-1}$ or higher depending on the specific materials [1].

In general, compressive pressure [45] and numbers of HPT turns [46,47] are the critical parameters for conventional HPT processing. For the present HPT procedure, beside 
these experimental parameters, sample set-up also influences the efficiency of phase mixture. Thus, a preliminary study on the effect of the number of layers was conducted at the macroscale on the Al-Mg system processed by HPT. Specifically, a total of five disks of the Al and $\mathrm{Mg}$ samples, having the same consistent thickness of $\sim 0.8 \mathrm{~mm}$, were stacked in the order of $\mathrm{Al} / \mathrm{Mg} / \mathrm{Al} / \mathrm{Mg} / \mathrm{Al}$ and then the pile was processed by HPT for 10 turns under a pressure of 6.0 GPa at RT. A schematic illustration of the specific sample set-ups with five stacked disks and three stacked disks are shown in upper and lower in Fig. 5(a), respectively.

Figure 5(b) shows a vertical cross-section of the Al-Mg system after HPT for 10 turns at $6.0 \mathrm{GPa}$ from the five stacked disks (upper) and a similar result for the same Al-Mg system from three stacked disks processed by HPT for 20 turns under the same pressure of $6.0 \mathrm{GPa}$ (lower). Inspection shows that there is an excellent consistency in the microstructural formation in these sample appearances where the central region after HPT has clear separations of the $\mathrm{Al}$ and $\mathrm{Mg}$ phases but the changes at $r \approx 2.5 \mathrm{~mm}$ towards a complex mixture with flow turbulence of ultrafine $\mathrm{Al}$ and $\mathrm{Mg}$ phases at the edges of both disks. Accordingly, it is reasonable to conclude in the preliminary study that alternative stacking of larger numbers of dissimilar metal disks will be effective for rapidly achieving a metal mixture, and ultimately a fast rate of atomic diffusion during processing by HPT. It should be noted that the higher numbers of disks in processing by HPT in principle fails to maintain the initial large volume of the sample as shown in Fig. 5(b) where the three and five disks stacking give similar final sample thicknesses and this result is contrary to the basic principles of processing by SPD which is anticipated to maintain the sample volume without any significant change after deformation. Nevertheless, the new processing procedure of HPT opens up the potential for using the HPT processing in the synthesizing of new types of metal systems including metal matrix nanocomposites.

\section{B. Future potential of the HPT technique for synthesizing new metal systems}


It is demonstrated in the present summary that the rapid diffusivity of $\mathrm{Mg}$ atoms into the $\mathrm{Al}$ matrix is a key process for the diffusion bonding of $\mathrm{Al}$ and $\mathrm{Mg}$ and for the formation of intermetallic compounds through the HPT processing at ambient temperature. Experimental demonstrations were documented in earlier reports providing the evidence for enhanced atomic diffusion in nanostructured materials processed by ECAP [48] and HPT [20,49]. The fast diffusivity in these processed materials may be attributed to the processing conditions including severe hydraulic pressure with a limited temperature rise [20] and torsional stress [49] during HPT processing and to the severe microstructural distortion introducing the high population of lattice defects produced in the nanostructure [48]. An earlier review describes the significance of the fast atomic mobility within UFG metals by recognizing the significant increase in the vacancy concentration through SPD processing [50]. It should be noted that a temperature increase during HPT processing is critical in terms of atomic diffusion and in practice very limited temperature increases were measured for several different metals in the very early stages of HPT processing for $<1$ turn [51]. Therefore, the present approach is reasonable.

There were only limited numbers of demonstrations for the fabrication of new metal systems through bonding dissimilar bulk metals by utilizing conventional HPT processing. A first report demonstrated a solid-state reaction in an $\mathrm{Al}-\mathrm{Cu}$ system through the bonding of semi-circular half-disks of commercial purity $\mathrm{Al}$ and $\mathrm{Cu}$ using HPT at ambient temperature for up to 100 turns [52]. A similar approach was later applied for forming a spiral texture by processing of an Al-Cu hybrid material though HPT where four quarter-disks, including two of pure $\mathrm{Cu}$ and two of an Al-6061 alloy, were positioned to make a complete disk and then processed by HPT at RT for 1 turn [53]. Thereafter, HPT for the bonding of separate Al and Mg disks was processed by stacking a set of two disks for up to 20 turns [54] and stacking three disks for 5-20 turns [20-23] for producing bi-layered and multi-layered structures, 
respectively, at RT. This strategy of HPT was even expanded recently to a set of alternately stacked $19 \mathrm{Cu}$ foils and $18 \mathrm{Ta}$ thin foils for forming a bulk solid under a pressure of $4 \mathrm{GPa}$ for up to 150 turns [55].

For examining the feasibility of the HPT processing for fabricating new metal systems, a preliminary study was performed for producing an $\mathrm{Al}-\mathrm{Cu}, \mathrm{Al}-\mathrm{Fe}$ and $\mathrm{Al}-\mathrm{Ti}$ systems using commercial purity $\mathrm{Al}, \mathrm{Cu}, \mathrm{Fe}$ and $\mathrm{Ti}$ metals. The consistent sample set-up with alternate stacking of three disks was used for this study and the overviews of the Al-Cu system after 10 and 60 turns at $6.0 \mathrm{GPa}, \mathrm{Al}-\mathrm{Fe}$ system for 20 turns at $1.0 \mathrm{GPa}$, and Al-Ti system after 50 turns at 6.0 GPa are shown in left in Fig. 6(a)-(c), respectively. It should be noted that at the central regions in all metal disks the bright regions denote the Al-rich phases and the dark regions correspond to the $\mathrm{Cu}$-rich, Fe-rich and Ti-rich phases in the micrographs in Fig. 6(a)(c), respectively, whereas the grey color at the overall disk edges may describe a complex phase mixture of $\mathrm{Al}$ and these dissimilar metals.

There is a consistent trend of microstructural evolution between these examples and the Al-Mg system after HPT as shown in Fig. 1. Especially, the trend of the complex phase mixture with increasing numbers of HPT turns in the Al-Cu system is in an excellent consistency with the Al-Mg system in macro-scale. Thus, the central regions with large multi-layered phases are reduced from $\mathrm{r}>4.0 \mathrm{~mm}$ to $\mathrm{r} \approx 1.0 \mathrm{~mm}$ with increasing numbers of turns from 10 to 60 turns in the Al-Cu system through HPT.

The variation of the Vickers microhardness for the Al-Cu system is shown in right of Fig. 6(a) where the hardness values were taken at the mid-plane along the disk diameters after HPT for 10 and 60 turns and the hardness of the base materials of $\mathrm{Al}$ and $\mathrm{Cu}$ after $10 \mathrm{HPT}$ turns are denoted by the dashed lines at $\mathrm{Hv} \approx 65$ and $\sim 150$, respectively. The central regions of $r<3.0-4.0 \mathrm{~mm}$ after 10 turns and $r<1.0 \mathrm{~mm}$ after 60 turns where the areas hold the layered microstructure as seen in Fig. 6(a) demonstrated the lower hardness values which are 
consistent with the hardness of the base material of $\mathrm{Cu}$ when processed separately by HPT for 10 turns. In contrast, the hardness at the peripheral regions recorded exceptionally high hardness values of $\mathrm{Hv} \approx 250$ and 500 with increasing numbers of turns to 10 and 60 , respectively, and these are not attainable hardness when the base materials are simply processed by HPT separately for grain refinement. Although further studies are necessary to investigate the detailed compositional changes through the diffusion bonding during HPT, it is expected the formation of new $\mathrm{Al}-\mathrm{Cu}$ system with possible new phases demonstrating exceptional hardness after HPT.

On contrary, the Al-Fe and Al-Ti systems are presented as examples for the metal systems without synthesizing any new phases in the current processing conditions used in the preliminary study. In practice, the color-coded hardness contour maps in Fig. 6(b) and (c) show that the highly deformed disk edges at $r>4.0 \mathrm{~mm}$ demonstrated the highest hardness of $\mathrm{Hv} \approx 330$ and $\approx 350$ in the Al-Fe and Al-Ti systems, respectively, after HPT. These hardness values are reasonably consistent with the upper saturated hardness for the pure $\mathrm{Fe}$ and $\mathrm{Ti}$ when processed separately for more than 4 HPT turns without any phase transformation [56]. Moreover, the XRD profiles shown in Fig. 6(b) and (c) are taken at the slightly polished disk surfaces of the Al-Fe and Al-Ti system after processing and the analysis suggests the presences of individual $\mathrm{Al}, \mathrm{Fe}$ and $\mathrm{Ti}$ phases without any formation of new intermetallic compound phases in these metal systems after HPT.

It should be noted that the formation of Al-Ti alloy systems with the nucleation of intermetallic phases was reported earlier using the mechanical alloying approach with metal powders processed by HIP [57] and HPT [58]. The successful nucleation of intermetallic phases in these investigations was due to the much shorter required diffusion lengths for the nucleation of such new phases by comparison with the present experiments which demonstrate the bulk reaction of metals. Thus, the last two examples on the bulk reactions of 
the Al-Fe and Al-Ti systems failed to demonstrate evidence for introducing any new phases during the HPT processing. However, as seen in the overview of the microstructure in Fig. 6(b) and (c), the capability of the HPT procedure for diffusion bonding and complex mixing of these dissimilar two metal combinations are phenomenal as a RT manufacturing technique in the view point of diffusion bonding, welding and mechanical joining technologies [59]. Moreover, the synthesized microstructure in all metal systems processed by HPT demonstrate a unique microstructural gradation from the disk edges to the centers due to the concurrent occurrence of diffusion bonding of the dissimilar metals and the complex metal flow by the torsional deformation.

These materials can be defined as heterostructured nanomaterials [36] involving heterogeneous and gradient microstructures in terms of grains, phases and compositions from the sample surfaces to the depth $[60,61]$. This is a new category of bulk engineering materials and the formation of heterostructure in bulk metals leads to a significant potential for exhibiting excellent mechanical properties and functionalities [62-64] that will extend the capability and future applications of bulk nanostructured materials processed by the SPD technique. Thus, the present report outlines a significant potential for applying and utilizing the HPT processing for the synthesis of new alloy systems containing heterostructure, especially by simply and expeditiously fabricating a wide range of MMNCs from simple metals and alloys. Incorporating an additional treatment of PDA, the new metal systems can further improve the mechanical properties for the desired applications.

\section{SUMMARY AND CONCLUSIONS}

1. The synthesis of an MMNC by forming intermetallic compounds was demonstrated in an Al-Mg system using HPT for up to 20 turns through diffusion bonding of separate $\mathrm{Al}$ and $\mathrm{Mg}$ disks. The significance of applying PDA was demonstrated at the disk edges by improving 
the strain rate sensitivity leading to an excellent potential for achieving high plasticity in the Al-Mg system after HPT for 20 turns.

2. The synthesized MMNCs in the Al-Mg system demonstrated decreasing density and increasing hardness with increasing numbers of HPT turns through 5-20 turns, thus exhibiting an excellent potential for the HPT processing to fabricate new metal systems with exceptionally high strength-to-weight ratios. Moreover, HPT may improve and accelerate the metal mixture by increasing the total stacking numbers of dissimilar metal disks.

3. It is defined that in general the microstructure across the diameters of the HPT-processed disks demonstrate different scales of multi-layered structures consisting of large phases of two dissimilar metals at the disk centers and the phases in the submicrometer level at the disk edges. Increasing numbers of HPT turns tends to expand the peripheral region with the severe phase mixture and ultimately forming intermetallic phases. Thus, there is the feasibility of HPT for the formation of heterostructure in bulk nanostructured metals leading to excellent mechanical properties and the expansion in the future applications of the bulk nanostructured materials.

4. Preliminary studies for making use of HPT was demonstrated for synthesizing Al-Cu, $\mathrm{Al}-\mathrm{Fe}$ and $\mathrm{Al}-\mathrm{Ti}$ systems. The Al-Cu system exhibited exceptional strength at the disk periphery through 60 turns with exhibiting gradual development of heterostructure by increasing HPT turns. In contrast, Al-Fe for 20 turns and Al-Ti through 50 turns failed to show the improved hardness at the disk edges without any proof of new phase nucleation whereas the heterostructure was observed across the disk diameters. Nevertheless, the HPT processing has a considerable potential for the joining technique for bonding dissimilar metals at room temperature. 


\section{ACKNOWLEDGEMENTS}

This work was supported in part by the National Research Foundation of Korea (NRF) grants funded by the Ministry of Science and ICT (No. 2015R1A5A1037627 and No.

2017R1A2B4012255) (DHL and JIJ) and in part by the European Research Council under ERC Grant Agreement No. 267464-SPDMETALS (TGL). 


\section{REFERENCES}

1. K Lu: The future of metals. Science. 328, 319 (2010).

2. P.V. Liddicoat, X.Z. Liao, Y.T. Zhu, Y.H. Zhao, E.J. Lavernia, M.Y. Murashkin, R.Z. Valiev and S.P. Ringer: New hierarchy of solute architecture breaks strength ceiling in a nanocrystalline aluminium alloy. Nature Commun. 1, 63/1 (2010).

3. R.Z. Valiev, R.K. Islamgaliev and I.V. Alexandrov: Bulk nanostructured materials from severe plastic deformation. Prog. Mater. Sci. 45, 103 (2010).

4. $\quad$ R.Z. Valiev, Y. Estrin, Z. Horita, T.G. Langdon, M.J. Zehetbauer and Y.T. Zhu: Fundamentals of superior properties in bulk nanoSPD materials. Mater. Res. Lett. 4, 1 (2016).

5. Y. Estrin and A. Vinogradov: Extreme grain refinement by severe plastic deformation: A wealth of challenging science. Acta Mater. 651, 782 (2013).

6. A.P. Zhilyaev and T.G. Langdon: Using high-pressure torsion for metal processing: Fundamentals and applications. Prog. Mater. Sci. 53, 893 (2008).

7. T.G. Langdon: Twenty-five years of ultrafine-grained materials: Achieving exceptional properties through grain refinement. Acta Mater. 61, 7035(2013).

8. A.V. Korznikov, O. Dimitrov, G.F. Korznikova, J.P. Dallas, A. Quivy, R.Z. Valiev and A. Mukherjee: Nanocrystalline structure and phase transformation of the intermetallic compound TiAl processed by severe plastic deformation. Nanostruct. Mater. 11, 17 (1999).

9. N.V. Kazantseva, N.V. Mushnikov, A.G. Popov, P.B. Terent'ev and V.P. Pilyugin: Severe plastic deformation and hydrogenation of the titanium aluminides. J. Alloys. Compds. 509, 9307 (2011).

10. B. Srinivasarao, A.P. Zhilyaev, R. Muñoz-Moreno and M.T. Pérez-Prado: Effect of high pressure torsion on the microstructure evolution of a gamma Ti-45Al-2Nb-2Mn0.8 vol\% $\mathrm{TiB}_{2}$ alloy. J. Mater. Sci. 48, 4599 (2013).

11. J.-K. Han, X. Li, R. Dippenaar, K.-D. Liss and M. Kawasaki: Microscopic plastic response in a bulk nano-structured TiAl intermetallic compound processed by highpressure torsion. Mater. Sci. Eng. A 714, 84 (2018) .

12. A.P. Zhilyaev, A.A Gimazov, G.I. Raab and T.G. Langdon: Using high-pressure torsion for the cold-consolidation of copper chips produced by machining. Mater. Sci. Eng. A 486, 123 (2008).

13. K. Edalati, Y. Yokoyama and Z. Horita: High-pressure torsion of machining chips and bulk discs of amorphous $\mathrm{Zr}_{50} \mathrm{Cu}_{30} \mathrm{Al}_{10} \mathrm{Ni}_{10}$. Mater. Trans. 51, 23 (2010).

14. A.V. Korznikov, I.M. Safarov, D.V. Laptionok and R.Z. Valiev: Structure and properties of superfine-grained iron compacted out of ultradisperse powder. Acta Metall. 
Mater. 39, 3193 (1991).

15. V.V. Stolyarov, Y.T. Zhu, T.C. Lowe, R.K. Islamgaliev and R.Z. Valiev: Processing nanocrystalline $\mathrm{Ti}$ and its nanocomposites from micrometer-sized $\mathrm{Ti}$ powder using high pressure torsion. Mater. Sci. Eng. A 282, 78 (2000).

16. K. Edalati, Z. Horita, H. Fujiwara, and K. Ameyama: Cold consolidation of ball-milled titanium powders using high-pressure torsion. Metall. Mater. Trans. A 41A, 3308 (2010).

17. J.M. Cubero-Sesin and Z. Horita: Powder consolidation of $\mathrm{Al}-10 \mathrm{wt} \% \mathrm{Fe}$ alloy by high-pressure torsion. Mater. Sci. Eng. A 558, 462 (2012).

18. Y. Zhang, S. Sabbaghianrad, H. Yang, T. Topping, T.G. Langdon, E.J. Lavernia, J.M. Schoenung and S. Nutt: Two-step SPD processing of a trimodal Al-based nanocomposite. Metall. Mater. Trans. A 46A, 5877 (2015).

19. A.P. Zhilyaev, G. Ringot, Y. Huang, J.M. Cabrera and T.G. Langdon: Mechanical behavior and microstructure properties of titanium powder consolidated by highpressure torsion. Mater. Sci. Eng. A 688, 498 (2017).

20. B. Ahn, A.P. Zhilyaev, H.-J. Lee, M. Kawasaki and T.G. Langdon: Rapid synthesis of an extra hard metal matrix nanocomposite at ambient temperature. Mater. Sci. Eng. A 635, 109 (2015).

21. B. Ahn, H.-J. Lee, I.C. Choi, M. Kawasaki, J.-I. Jang and T.G. Langdon: Micromechanical behavior of an exceptionally strong metal matrix nanocomposite processed by high-pressure torsion. Adv. Eng. Mater. 18, 1001 (2016).

22. M. Kawasaki, B. Ahn, H.-J. Lee, A.P. Zhilyaev and T.G. Langdon: Using high-pressure torsion to process an aluminum-magnesium nanocomposite through diffusion bonding. J. Mater. Res. 31, 88 (2016).

23. J.-K. Han, H.-J. Lee, J.-i. Jang, M. Kawasaki and T.G. Langdon: Micro-mechanical and tribological properties of aluminum-magnesium nanocomposites processed by highpressure torsion. Mater. Sci. Eng. A 684, 318 (2017).

24. R.B. Figueiredo, P.R. Cetlin and T.G. Langdon: Using finite element modeling to examine the flow processes in quasi-constrained high-pressure torsion. Mater. Sci. Eng. A 528, 8198 (2011).

25. M. Kawasaki: Different models of hardness evolution in ultrafine-grained materials processed by high-pressure torsion. J. Mater. Sci. 49, 18 (2014).

26. M. Kawasaki, S.N. Alhajeri, C. Xu and T.G. Langdon: The development of hardness homogeneity in pure aluminum and aluminum alloy disks processed by high-pressure torsion. Mater. Sci. Eng. A 529, 345 (2011).

27. H.-J. Lee, S.K. Lee, K.H. Jung, G.A. Lee, B. Ahn, M. Kawasaki and T.G. Langdon: Evolution in hardness and texture of a ZK60A magnesium alloy processed by high- 
pressure torsion. Mater. Sci. Eng. A 630, 90 (2015).

28. S. Samson: The crystal structure of the phase $\beta-\mathrm{Mg}_{2} \mathrm{Al}_{3}$. Acta Crystallogr. 19, 401 (1965).

29. L. Lutterotti: Total pattern fitting for the combined size-strain-stress-texture determination in thin film diffraction. Nucl. Instrum. Methods Phys. Res. Sect. B $\mathbf{2 6 8}$ 334 (2010).

30. B.N. Lucas and W.C. Oliver: Indentation power-law creep of high-purity indium. Metall. Mater. Trans. A 30A, 601 (1999).

31. S. Shim, J.-I. Jang and G.M. Pharr: Extraction of flow properties of single-crystal silicon carbide by nanoindentation and finite-element simulation. Acta Mater. 56, 3824 (2008).

32. R.Z. Valiev, I.V. Alexandrov, Y.T. Zhu and T.C. Lowe: Paradox of strength and ductility in metals processed by severe plastic deformation. J. Mater. Res. 17, 5 (2002).

33. R. Valiev: Materials science: nanomaterial advantage. Nature. 419, 887 (2002).

34. R. Valiev: Nanostructuring of metals by severe plastic deformation for advanced properties. Nat. Mater. 3, 511 (2004).

35. P. Kumar, M. Kawasaki and T.G. Langdon: Review: Overcoming the paradox of strength and ductility in ultrafine-grained materials at low temperatures. J. Mater. Sci. 51, 7 (2016).

36. I.A. Ovid'ko, R.Z. Valiev and Y.Z. Zhu: Review on superior strength and enhanced ductility of metallic nanomaterials. Prog. Mater. Sci. 94, 462 (2018).

37. J. Mueller, K. Durst, D. Amberger and M. Göken: Local investigations of the mechanical properties of ultrafine grained metals by nanoindentations. Mater. Sci. Forum 31, 503 (2006).

38. A. Böhner, V. Maier, K. Durst, H.W. Höppel and M. Göken: Macro- and nanomechanical properties and strain rate sensitivity of accumulative roll bonded and equal channel angular pressed ultrafine-grained materials. Adv. Eng. Mater. 13, 251 (2011).

39. V. Maier, B. Merle, M. Göken and K. Durst: An improved long-term nanoindentation creep testing approach for studying the local deformation processes in nanocrystalline metals at room and elevated temperatures. J. Mater. Res. 28, 1177 (2013).

40. J.M. Wheeler, V. Maier, K. Durst, M. Göken and J. Michler: Activation parameters for deformation of ultrafine-grained aluminium as determined by indentation strain rate jumps at elevated temperature. Mater. Sci. Eng. A 585, 108 (2013).

41. I.-C. Choi, D.-H. Lee, B. Ahn, K. Durst, M. Kawasaki, T.G. Langdon and J.-i. Jang: Enhancement of strain-rate sensitivity and shear yield strength of a magnesium alloy 
processed by high-pressure torsion. Scripta Mater. 94, 44 (2015).

42. M. Kawasaki, B. Ahn, P. Kumar, J.-i. Jang, T.G. Langdon, Nano- and micromechanical properties of ultrafine-grained materials processed by severe plastic deformation techniques, Adv. Eng. Mater. 19, 1600578(1-17) (2017).

43. R.Z. Valiev, A.V. Sergueeva and A.K. Mukherjee: The effect of annealing on tensile deformation behavior of nanostructured SPD titanium. Scripta Mater. 49, 669 (2003).

44. M. Kawasaki and T.G. Langdon: Using severe plastic deformation to fabricate strong metal matrix composites. Mater. Res. 20 (Suppl. 1), 46 (2017).

45. A.P. Zhilyaev, S. Lee, G.V. Nurislamova, R.Z. Valiev and T.G. Langdon: Microhardness and microstructural evolution in pure nickel during high-pressure torsion. Scripta Mater. 44, 2753 (2001).

46. H. Jiang, Y.T. Zhu, D.P. Butt, I.V. Alexandrov and T.C. Lowe: Microstructural evolution, microhardness and thermal stability of HPT-processed Cu. Mater. Sci. Eng. A 290, 128 (2000).

47. A.P. Zhilyaev, K. Oh-ishi, T.G. Langdon and T.R. McNelley: Microstructural evolution in commercial purity aluminum during high-pressure torsion. Mater. Sci. Eng. A 277, 410 (2005).

48. S.V. Divinski, G. Reglitz, H. Rösner, Y. Estrin and G. Wilde: Ultra-fast diffusion channels in pure Ni severely deformed by equal-channel angular pressing. Acta Mater. 59, 1974 (2011).

49. D.-H. Lee, I.-C. Choi, M.-Y. Seok, J. He, Z. Lu, J.-Y. Suh, M. Kawasaki, T.G. Langdon and J.-i. Jang: Nanomechanical behavior and structural stability of a nanocrystalline CoCrFeNiMn high-entropy alloy processed by high-pressure torsion. J. Mater. Res. 30, 2804 (2015).

50. X. Sauvage, G. Wilde, S.V. Divinski, Z. Horita and R.Z. Valiev: Review: Grain boundaries in ultrafine grained materials processed by severe plastic deformation and related phenomena. Mater. Sci. Eng. A 540, 1 (2012).

51. K. Edalati, Y. Hashiguchi, P.H.R. Pereira, Z. Horita, T.G. Langdon, Effect of temperature rise on microstructural evolution during high-pressure torsion, Mater. Sci. Eng. A 714, 167 (2018).

52. K. Oh-ishi, K. Edalati, H.S. Kim, K. Hono and Z. Horita: High-pressure torsion for enhanced atomic diffusion and promoting solid-state reactions in the aluminum-copper system. Acta Mater. 61, 3482 (2013).

53. O. Bouaziz, H.S. Kim and Y. Estrin: Architecturing of metal- based composites with concurrent nanostructuring: A new paradigm of materials design. Adv. Eng. Mater. 15, 336 (2013).

54. X. Qiao, X. Li, X. Zhang, Y. Chen, M. Zheng, I.S. Golovin, N. Gao and M.J. Starink: 
Intermetallics formed at interface of ultrafine grained $\mathrm{Al} / \mathrm{Mg}$ bi-layered disks processed by high pressure torsion at room temperature. Mater. Lett. 181, 187 (2016).

55. N. Ibrahim, M. Peterlechner, F. Emeis, M. Wegner, S.V. Divinski and G. Wilde: Mechanical alloying via high-pressure torsion of the immiscible Cu50Ta50 system. Mater. Sci. Eng. A 685, 19 (2017).

56. K. Edalati and Z. Horita: Universal plot for hardness variation in pure metals processed by high-pressure torsion. Mater. Trans. 51, 1051 (2010).

57. Z. Lee, S.R. Nutt, R. Rodriguez, R.W. Hayes, E.J. Lavernia, Microstructural evolution and deformation of cryomilled nanocrystalline Al-Ti-Cu Alloy, Metall. Mater. Trans. A 34A, 1473 (2003).

58. K. Edalati, S. Toh, H. Iwaoka, M. Watanabe, Z. Horita, D. Kashioka, K. Kishida, H. Inui, Ultrahigh strength and high plasticity in TiAl intermetallics with bimodal grain structure and nanotwins, Scripta Mater. 67, 814 (2012).

59. K. Martinsen, S.J. Hu and B.E. Carlson: Joining of dissimilar materials. CIRP Annals. 64, 679 (2015).

60. X.L. Wu, P. Jiang, L. Chen, J.F. Zhang, F.P. Yuan and Y.T. Zhu: Synergetic strengthening by gradient structure. Mater. Res. Lett. 2, 185 (2014).

61. K. Lu: Making strong nanomaterials ductile with gradient. Science 345, 1455 (2014).

62. X.L. Wu, P. Jiang, L. Chen, F.P. Yuan and Y.T. Zhu: Extraordinary strain hardening by gradient structure. Proc. Natl. Acad. Sci. USA 111, 7197 (2014).

63. Y. Liu, B. Jin and J. Lu: Mechanical properties and thermal stability of nanocrystallized pure aluminum produced by surface mechanical attrition treatment. Mater. Sci. Eng. A 636, 446 (2015).

64. X. Wu and Y. Zhu: Heterogeneous materials: a new class of materials with unprecedented mechanical properties, Mater. Res. Lett. 5, 527 (2017). 
Table I The measured density, the maximum Vickers hardness value, and the estimated strength-to-weight ratio for the MMNCs in the Al-Mg system after HPT for 5-20 turns and the reference materials of Al-1050 and ZK60 alloys after HPT for 5 turns [44].

Reprinted with permission from Ref. 44.

\begin{tabular}{cccc}
\hline Materials & $\begin{array}{c}\text { Density } \\
\left(\mathrm{g} \mathrm{cm}^{-3}\right)\end{array}$ & $\begin{array}{c}\text { Maximum hardness } \\
(\mathrm{Hv})\end{array}$ & $\begin{array}{c}\text { Strength-to-weight ratio } \\
\left(\mathrm{MPa} \mathrm{cm}^{3} \mathrm{~g}^{-1}\right)\end{array}$ \\
\hline MMNC after 5 HPT turns & 2.50 & 130 & 170 \\
MMNC after 10 HPT turns & 2.48 & 270 & 350 \\
MMNC after 20 HPT turns & 2.34 & 330 & 455 \\
Al-1050 alloy after 5 turns & 2.73 & $65[26]$ & 80 \\
ZK 60 alloy after 5 turns & 1.84 & $110[27]$ & 190 \\
\hline
\end{tabular}




\section{Figure captions}

FIG. 1 OM micrographs for the disks of the Al-Mg alloy system after HPT for, from the top, 1, 5, 10, 20 turns and 20 turns followed by PDA at $573 \mathrm{~K}$ for 1 hour, respectively [20-23]. The color-corded hardness contour maps [20,23] are overlapped with the right half of each OM micrograph. $<$ Color online $>>$ Reprinted with permissions from Ref. 20-23.

FIG. 2 TEM bright-field images taken at the Al-Mg disk edges after HPT for (a) 5 turns and (b)10 turns and (c) the XRD profile with the MAUD estimation for the disk edge after 10 HPT turns [20]. Reprinted with permission from Ref. 20.

FIG. 3 Representative TEM bright-field images taken at the disk edges after $(a-b)$ HPT for 20 turns and (c) HPT followed by PDA in the Al-Mg system and the X-ray diffraction profiles for the disk edges of the Al-Mg system after (d) HPT for 20 turns and (e) HPT and PDA [23]. Reprinted with permission from Ref. 23.

FIG. 4 (a) Representative load-displacement curves at four strain rates and (b) Variations of the strain rate sensitivity with increasing strain rate for the Al-Mg disk edges after HPT for 20 turns and HPT and PDA [23]. Reprinted with permission from Ref. 23. $<<$ color online $>>$

FIG. 5 (a) Schematic illustrations of the sample set-ups for five stacked disks (upper) and three stacked disks (lower) and (b) vertical cross-sections of the Al-Mg system with the five stacked disks after HPT for 10 turns at $6.0 \mathrm{GPa}$ (upper) and with three stacked disks processed by HPT for 20 turns under at 6.0 GPa (lower).

FIG. 6 (a) A cross-section (left) and Vickers hardness variation (right) for the Al-Cu system after 10 and 60 turns at $6.0 \mathrm{GPa}$, and (b) and (c) overviews of (left) and the XRD profiles for the Al-Fe system for 20 turns at $1.0 \mathrm{GPa}$ and Al-Ti system after 50 turns at 6.0 GPa, respectively. <<Color online>> 


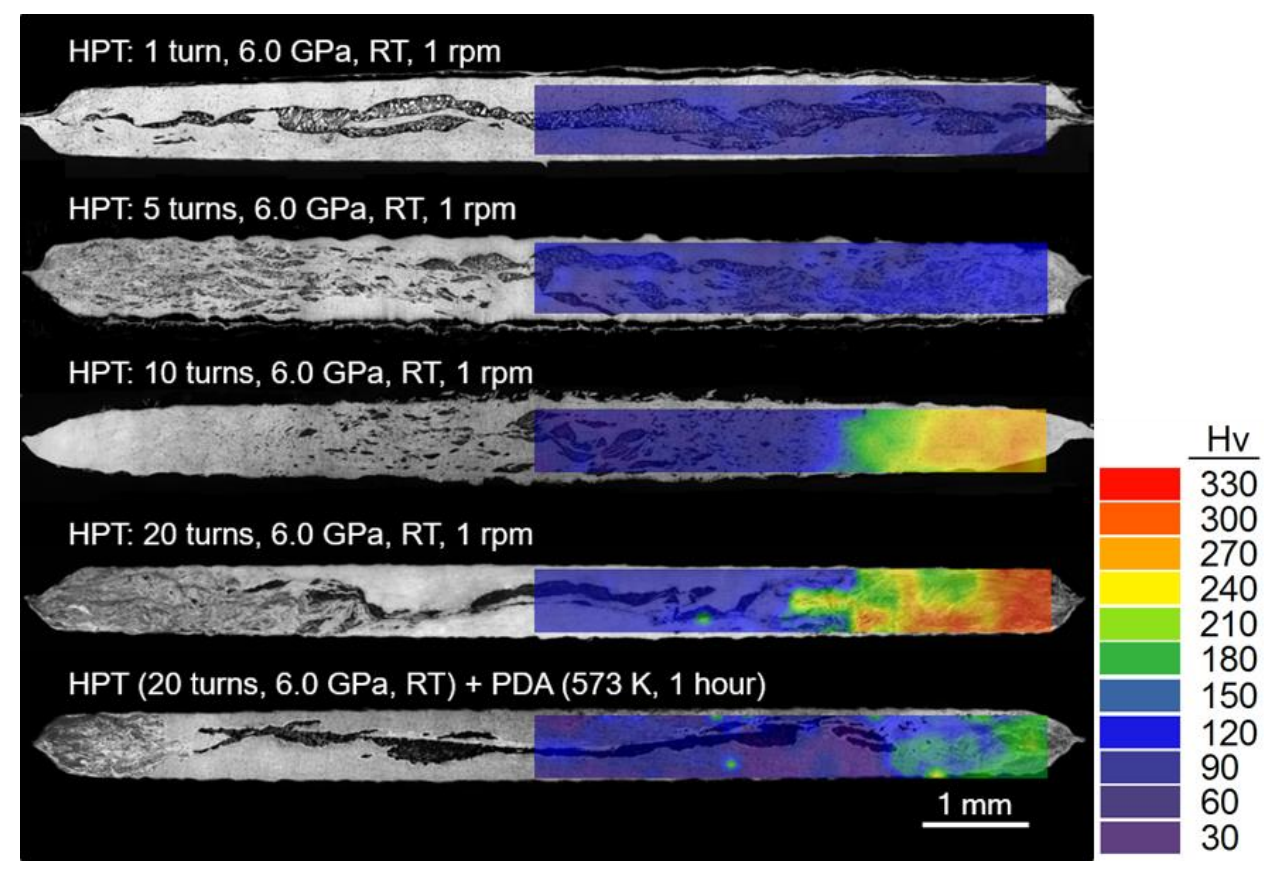

Fig. 1 


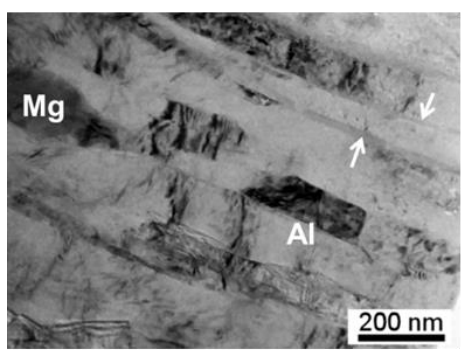

(a)

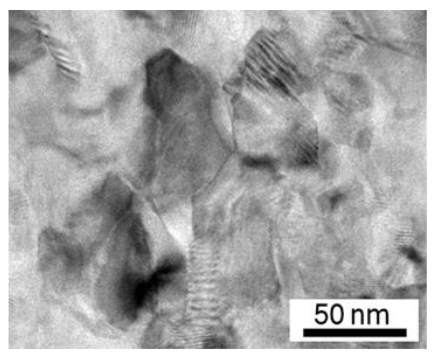

(b)

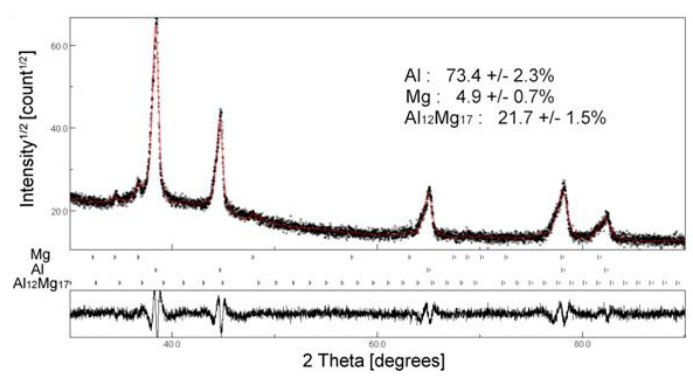

(c)

Fig. 2 


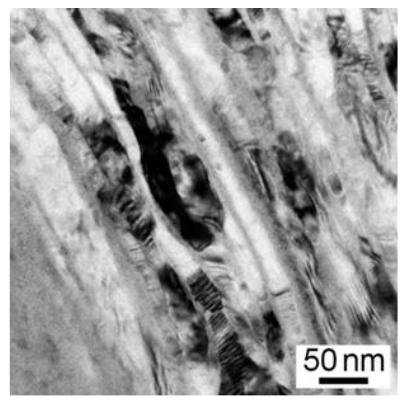

(a)

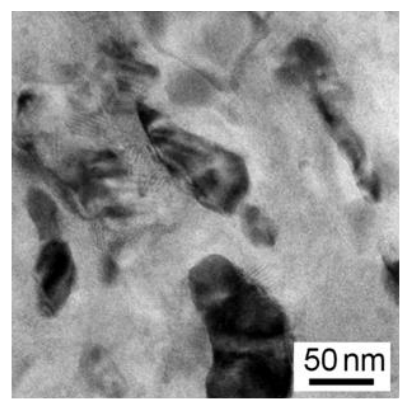

(b)

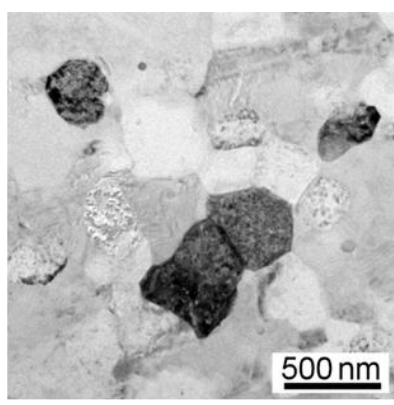

(c)

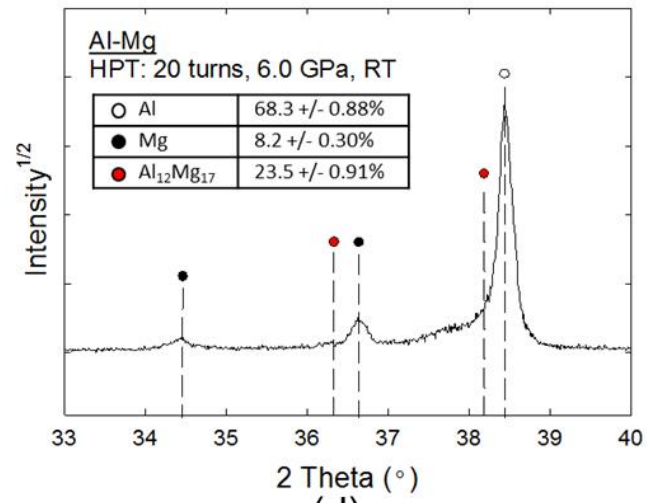

(d)

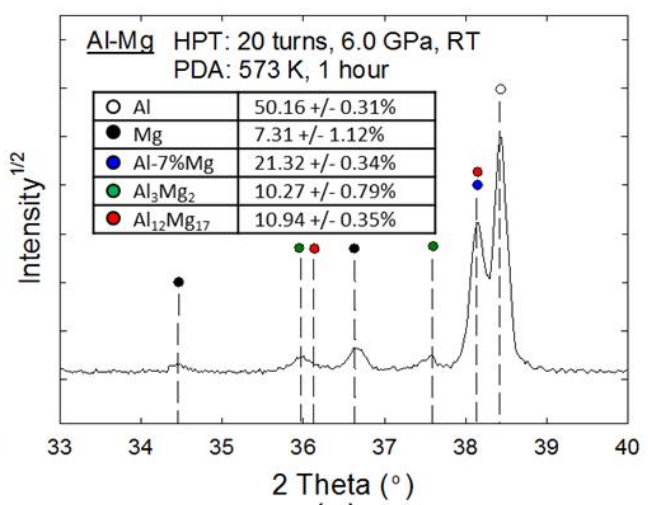

(e)

Fig. 3 


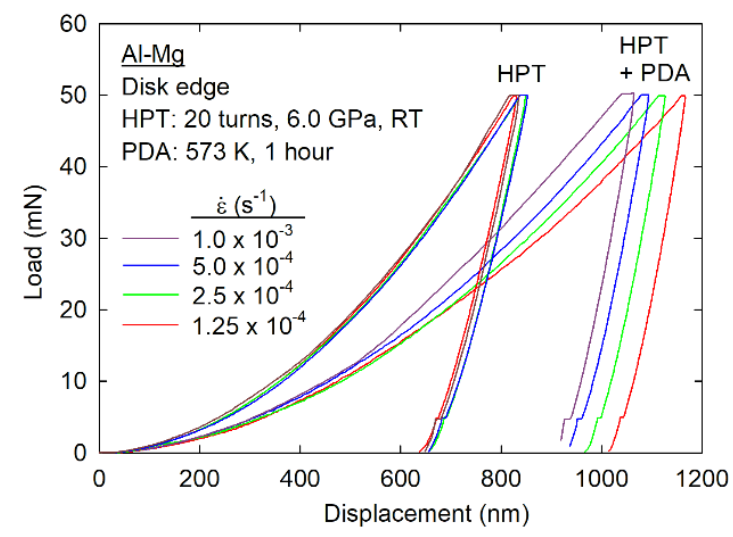

(a)

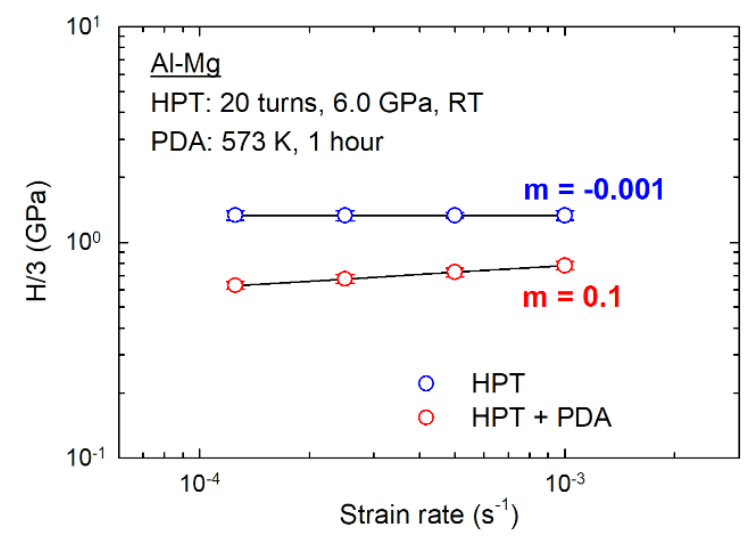

(b)

Fig. 4 


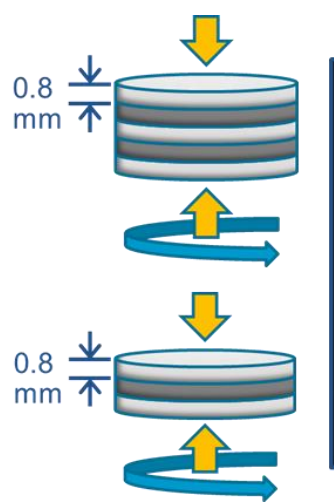

(a)

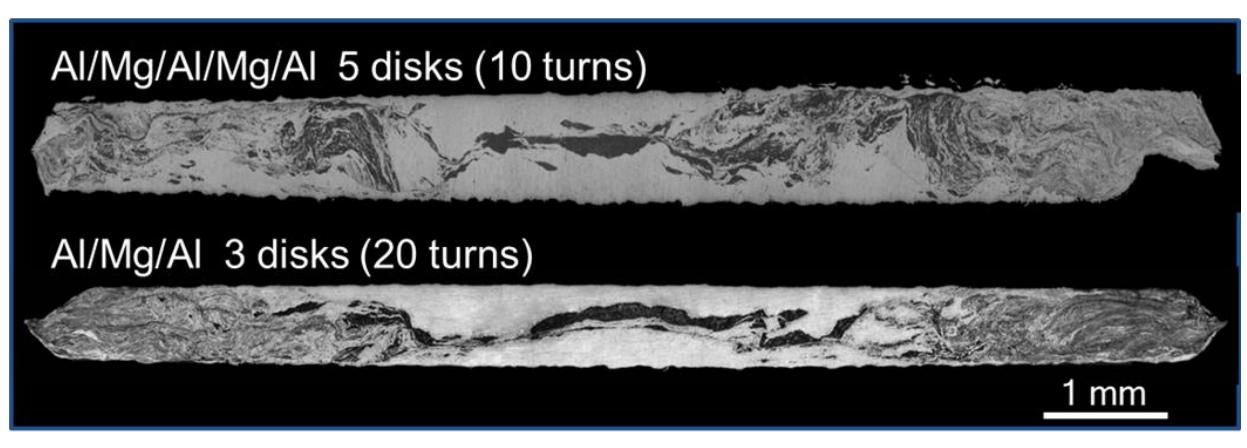

(b)

Fig. 5 


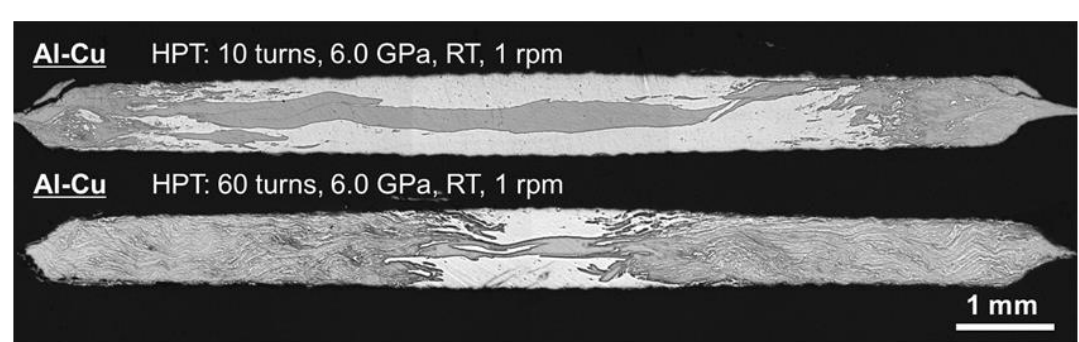

(a)

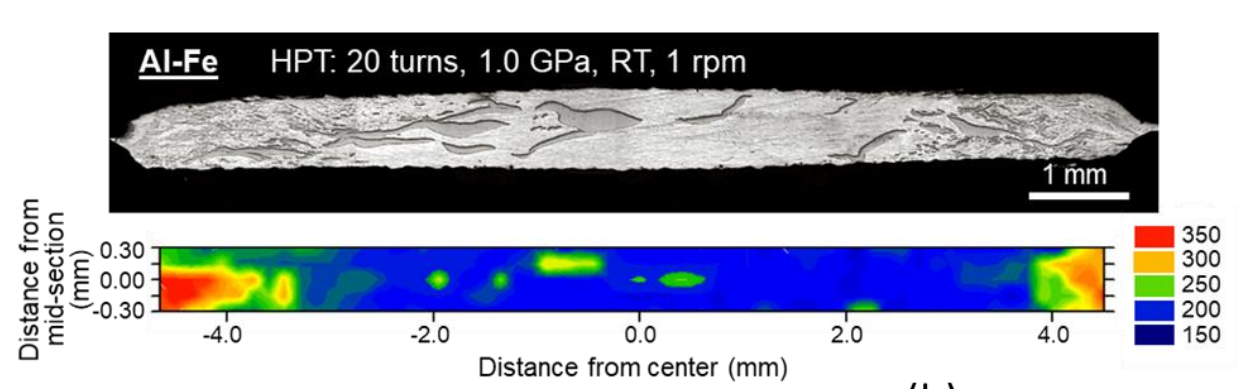

(b)
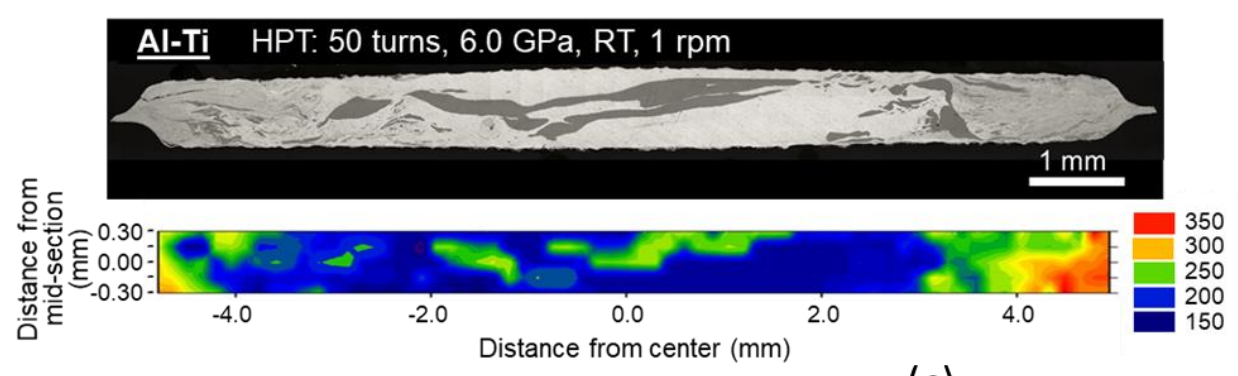

(c)
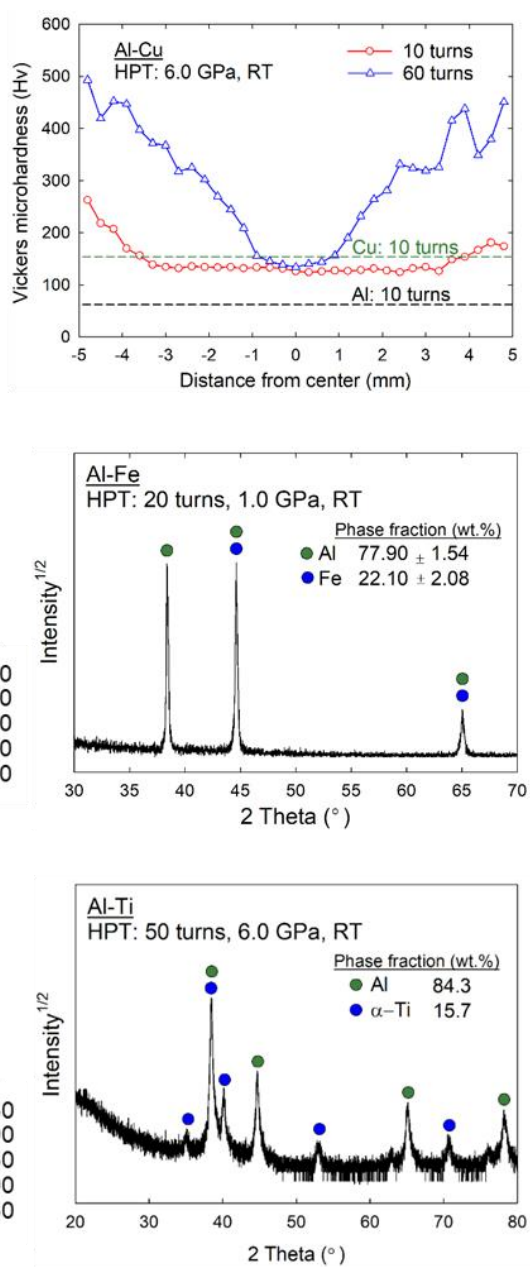

Fig. 6 